\title{
Observing the north polar ionosphere on 30 October 2003 by GPS imaging and IS radars
}

\author{
C. Stolle ${ }^{1}$, J. Lilensten ${ }^{2}$, S. Schlüter ${ }^{3}$, Ch. Jacobi ${ }^{4}$, M. Rietveld ${ }^{5}$, and H. Lühr ${ }^{1}$ \\ ${ }^{1}$ GeoForschungsZentrum Potsdam, Telegrafenberg, 14473 Potsdam, Germany \\ ${ }^{2}$ Laboratoire de Planétologie de Grenoble, BP 53, 38041 Grenoble cedex, France \\ ${ }^{3}$ DLR, Institute of Communications and Navigation, Kalkhorstweg 53, 17235 Neustrelitz, Germany \\ ${ }^{4}$ Institute for Meteorology, University of Leipzig, Stephanstr. 3, 04103 Leipzig, Germany \\ ${ }^{5}$ EISCAT, Ramfjordmoen, 9027 Ramfjordbotn, Norway
}

Received: 4 May 2005 - Revised: 23 September 2005 - Accepted: 28 November 2005 - Published: 7 March 2006

\begin{abstract}
The evening of 30 October 2003 was subject to a major storm main phase. For this time, we combine largescale electron content maps from GPS imaging with time series of electron density and temperature of two EISCAT radars in Troms $\varnothing$ and Svalbard and the Sondrestrom radar, for observing the north polar ionosphere. The GPS assimilations resulted in the image of the electron content trace of an anti-sunward polar Tongue Of Ionisation (TOI) consecutively to 20:00 UT. In combination with the radar observations we concluded that the TOI persisted during the whole period of continuous southward IMF $B_{z}$ until about 22:40 UT while its largest extension toward the nightside auroral region was found between 21:00-22:00 UT. A typical F region electron temperature of $\sim 2000 \mathrm{~K}$ and the plasma velocity of $\sim 800 \mathrm{~ms}^{-1}$ support its convective origin from the dayside mid-latitudes. Due to the structured appearance of the electron content distribution and the radar electron density time series we believe that discrete plasma patches formed inside the anti-sunward drift pattern. After two large oscillations of the IMF $B_{z}$ the nightside plasma density was observed to re-enhance after 23:00 UT along a longitudinal band below $70^{\circ} \mathrm{N}$. Coinciding electron temperatures of $\sim 2000 \mathrm{~K}$ suggest again the convective nature of the plasma, while a modified convection pattern is expected.
\end{abstract}

Keywords. Ionosphere (Polar ionosphere; Ionospheric disturbances; Plasma convection)

\section{Introduction}

The evening of 30 October 2003 was part of a very active space weather period during October and November 2003 (Gopalswamy et al., 2005). It was assigned to a magnetic storm main phase starting at 18:00 UT, with peaking hourly $D_{s t}=-401$ at 23:00 UT. During

Correspondence to: C. Stolle

(stolle@gfz-potsdam.de) that time an intensive positive ionospheric storm was observed in coincidence with a decreasing Interplanetary Magnetic Field (IMF) when vertical TEC with over 100 TECU ( 1 TEC Unit $=10^{16}$ electrons $/ \mathrm{m}^{2}$ ) were reported at dayside low- and mid-latitudes (e.g. Foster and Rideout, 2005; Chi et al., 2005; Zhao et al., 2005). Using an array of GPS (Global Positioning System) receivers spread over North America, Foster and Rideout (2005) observed a storm enhanced density (SED) event with as large TEC values reaching $65^{\circ}$ magnetic latitude at 20:00 UT.

The streaming of the low-latitude SED F region plasma into the polar cap was reported as a source for high latitude plasma content (Foster, 1993). Such enhanced density plumes have a typical $\mathrm{F}$ region electron temperature of 2000$2500 \mathrm{~K}$ and an anti-sunward velocity of $\sim 800 \mathrm{~ms}^{-1}$ (Foster et al., 2005). The SED streaming is one possible source for anti-sunward directed cross polar cap tongues of ionisation (TOI). They may develop during southward IMF (IMF $B_{z}<0$ ), when reconnection processes between the IMF and the Earth's magnetic field occur (Dungey, 1961). In the antisunward plasma drift pattern the formation of discrete polar cap plasma density enhancements or patches have frequently been observed by local instrumentation (e.g. Weber et al., 1985; Valladares et al., 1994) and were subject to model studies (e.g. Sojka et al., 1993, 1994). Recently, experimental evidence of different large-scale TOI events could be monitored across the polar cap from their electron content traces based on navigational measurements (Kersley et al., 2005; Stolle et al., 2005a) and together with plasma drift data (Foster et al., 2005).

For the evening of 30 October 2003, Mitchell et al. (2005) provided GPS TEC observations of the north polar ionosphere, reporting a narrow stream of enhanced electron content across the polar cap between 21:00-21:30 UT. The plasma distribution they found was in good agreement with a north polar convection pattern obtained from the Weimer (2001) model. They also proposed the convecting plasma to originate from dayside mid-latitudes. 

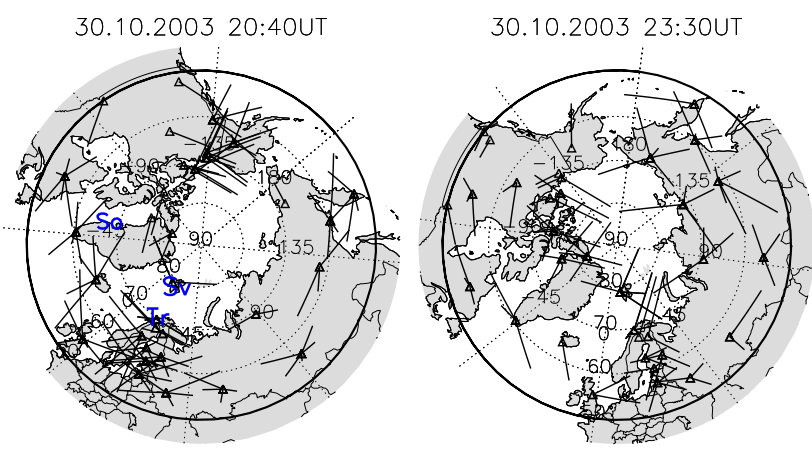

Fig. 1. GPS ray availability for two assimilation times. Black triangles give the location of the GPS receivers and black lines show the ground track of the rays. The blue letters give the locations of the Troms $\varnothing(\mathrm{Tr})$, Svalbard (Sv), and Sondrestrom (So) radars. Geographic coordinates are displayed. The maps are oriented with local noon which points to the top of the panel.

At the 35th COSPAR Assembly in July 2004 two further papers reported on observations of the north polar ionosphere during the evening of 30 October (Stolle et al., 2005b; Barthélemy et al., 2004). Using a three-dimensional (3-D) GPS based imaging tool, Stolle et al. (2005b) showed TEC maps of the electron content trace of a TOI consecutively to 20:00 UT. Their structure includes a discrete plasma enhancement imaged toward night at successive times. The nightside TEC re-enhanced before midnight. Barthélemy et al. (2004) presented data from two EISCAT (European Incoherent SCATter) radars at Svalbard and at Troms $\varnothing$. They observed two successive $\mathrm{F}$ region plasma enhancements which were found to coincide well with those shown by Stolle et al. (2005b), in time and location. Our paper aims to combine both reports into one discussion and includes observations of the Sondrestrom radar in Greenland, as well. By including these radar observations, the large-scale TEC maps may be completed, allowing a more comprehensive view on the north polar ionosphere during the evening.

\section{Data}

The applied 3-D ionospheric imaging uses an iterative Multiplicative Algebraic Reconstruction Techniques to assimilate calibrated GPS TEC observations into electron density fields modelled by a combination of the International Reference Ionosphere (Bilitza, 1990, 2001) and the plasmaspheric Global Core Plasma Model (Gallagher et al., 2000). The north polar assimilation area is specified from $50^{\circ} \mathrm{N}$ northwards, between 80 and $1000 \mathrm{~km}$ in altitude. A grid resolution of $\Delta l o n=10^{\circ}, \Delta l a t=4^{\circ}$, and $\Delta a l t=20 \mathrm{~km}$ is applied. This resolution is predefined by the GPS data availability in the north polar region. It is suitable to image large-scale electron density fields and ionospheric processes. The detailed description of the assimilation process, including careful validation work, is given in Stolle (2004) and Stolle et al. (2005) ${ }^{1}$. For instance, in comparison with in-situ electron density measurements, a mean bias of the assimilation results of $1.2110^{11} \mathrm{~m}^{-3}$ with an rms of $1.5610^{11} \mathrm{~m}^{-3}$ is given.

Ground-based TEC measurements from GPS observations provided by the International GPS Service (IGS) and the Scripps Orbit and Permanent Array Center (SOPAC) build the GPS database for the evening of 30 October 2003. There are $\sim 30 \pm 7$ GPS receivers available receiving signals from $1-$ 5 GPS satellites for each assimilation time. Calibrated TEC measurements from satellite-borne ionospheric radio occultation (IRO) experiments (Heise et al., 2005) are incorporated whenever they are available. For the following study, we make use of IRO data of the CHAMP (CHAllenging MiniSatellite Payload) mission (Reigber et al., 2002).

This paper relies on assimilation TEC maps which were produced for every $10 \mathrm{~min}$ during the evening. To obtain better temporal resolution, no integration of ground-based data was undertaken for any assimilation time, except for the included CHAMP occultation data. One occultation takes $\sim 6$ min. Figure 1 shows the ground-based data distribution for two assimilation times. The best receiver coverage is above Europe and Northern America. Between these two regions a data gap over Central Greenland exists, hence, no GPS information can be expected from there. The reliability of the assimilation results for the evening of 30 October is discussed in Stolle et al. (2005b). For instance, they showed reasonable agreement of the large-scale trend and the order of magnitude of TEC with radar observations above Svalbard.

The EISCAT mainland (UHF, $19.2^{\circ} \mathrm{E} / 69.6^{\circ} \mathrm{N}$ ) in Troms $\varnothing$ and the EISCAT Svalbard radar (ESR42, $16.5^{\circ} \mathrm{E} / 78.15^{\circ} \mathrm{N}$ ) operated during a French campaign between 29 October and 2 November 2003. The radar locations are indicated by the letters "Tr" and "Sv" on the left map in Fig. 1. For 30 October, radar observations during the full 24 hours are available and a 2-min integration was used for the data analysis. The Incoherent Scatter (IS) technique was described in detail in many publications (e.g. Rishbeth and van Eyken, 1993) and will therefore not be repeated here. The data result from alternating code programmes tau0 (ESR42) and tau2pl (Tromsø). The intrinsic range resolution of these programmes are 9 and $5 \mathrm{~km}$, respectively, but these are integrated to typically $20 \mathrm{~km}$ in height at $400 \mathrm{~km}$. The pointing of the antennas was along the prevailing geomagnetic field at $292 \mathrm{~km}$ altitude throughout the entire campaign. The UHF radar in Troms $\varnothing$ pointed with an elevation of $77.1^{\circ}$ and an azimuth of $184^{\circ}$. The ESR antenna pointing was $81.6^{\circ}$ in elevation and $181^{\circ}$ in azimuth. Therefore, presented $\mathrm{F}$ region electron densities and electron temperatures measured at Troms $\emptyset$ refer to about $100 \mathrm{~km}$ and those measured at Svalbard refer to about $80 \mathrm{~km}$ southward of the respective station.

In comparison with available colocated dynasonde measurements, an accuracy of roughly $\pm 20 \%$ of the UHF measurements are reported. At the time of our campaign, there

\footnotetext{
${ }^{1}$ Stolle, C., Schlüter, S., Heise, S., Jacobi, Ch., Jakowski, N. and Raabe, A.: A GPS based three-dimensional ionospheric imaging tool: process and assessment, Adv. Space Res., submitted, 2005.
} 


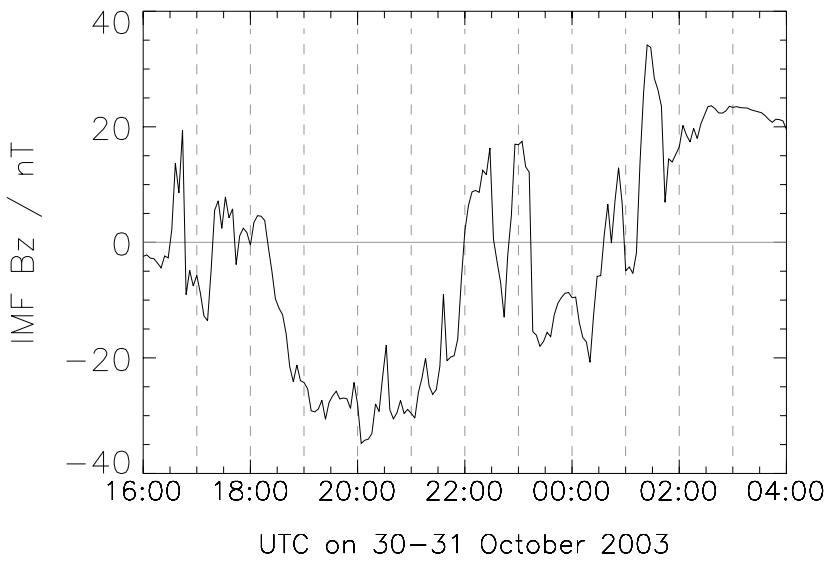

Fig. 2. Four minute averaged IMF $B_{z}$ at the ACE satellite (GSE coordinates).

was no operating ionosonde on Svalbard for possible synchronous measurements with ESR42. The calibration efforts for the Svalbard radars during the recent years are summarised in Stolle et al. (2004) and references therein. From their reports an accuracy of the absolute measurements of ESR42 within $\pm 10-20 \%$ can be assumed.

The EISCAT mainland experiment ran in tristatic mode. By that it is possible, in principle, to retrieve the full 3-D vector of the ion velocity. During the evening hours of $30 \mathrm{Oc}-$ tober, however, the 3-D velocity calculations reveal exceptional large uncertainties of up to $400 \%$ (C. Lathuillere, personal communication). Therefore, we did not consider this parameter here due to its unreliability at that time.

The IS Sondrestrom radar $\left(50.95^{\circ} \mathrm{W} / 66.99^{\circ} \mathrm{E}\right)$ was operated on the evening of 30 October, in response to a magnetic storm alert. The radar location is indicated in Fig. 1 by the letters "So". Simultaneous electron density and electron temperature data are available in $\sim 10$-min resolution, with a 3min integration for the data analyses. The range resolution was about $50 \mathrm{~km}$ in height at $400 \mathrm{~km}$. The antenna pointing for these measurements was $\sim 80^{\circ}$ in elevation and $\sim 140^{\circ}$ in azimuth. The radar sampled the $\mathrm{F}$ region, therefore, at about $80 \mathrm{~km}$ southeastward of the station. The description of the radar operation has been given by Kelly et al. (1995).

\section{Observations}

Figure 2 shows the $B_{z}$ component of IMF for the evening of 30 October 2003 monitored on board the ACE satellite. A southward turning of the IMF (IMF $B_{z}<0$ ) is observed at 18:20 UT. It reaches a minimum of $-34.7 \mathrm{nT}$ at 20:04 UT. The period of strong negative IMF $B_{z}$ lasts until 21:48 UT. Subsequently, two intensive drops of the IMF $B_{z}$ happened from $16 \mathrm{nT}$ at 22:28 UT to $-13 \mathrm{nT}$ at 22:44 UT, and from $17.5 \mathrm{nT}$ at 23:04 UT to $-18 \mathrm{nT}$ at 23:24 UT. Some minutes after 18:00 UT the solar wind speed at the ACE location rose above $1000 \mathrm{kms}^{-1}$ (c.f. Skoug et al., 2004). It stayed above these values at least until 24:00 UT. Hence, the IMF

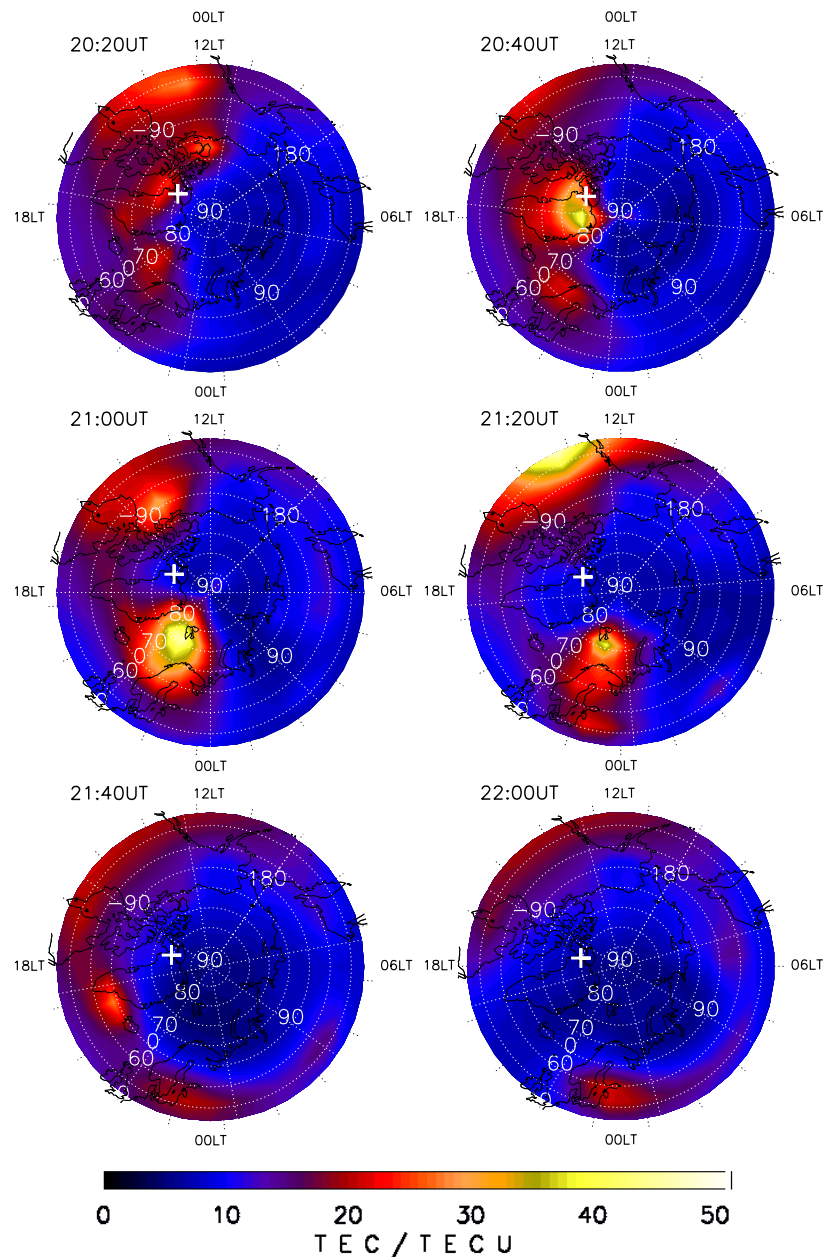

Fig. 3. Maps of vertical TEC re-integrated from north polar 3D electron density fields obtained by the assimilation of IGS and SOPAC ground data for 30 October 2003. If a black cross is given right next to the map, CHAMP IRO data are also assimilated. Geographic coordinates are displayed. The white plus sign indicates the location of the geomagnetic pole.

orientation observed at ACE location (L1 point) reached the magnetosphere in less than $30 \mathrm{~min}$.

North polar maps of vertical TEC, re-integrated from the 3-D GPS assimilations are shown in Fig. 3. They give snapshots between 19:40 UT and 22:00 UT of 30 October 2003 with a 20 -min resolution. The complete series of TEC assimilation maps is given in Stolle (2004). At 19:40 UT TEC values higher than 20 TECU $\left(1\right.$ TECU $\left.=10^{16} \mathrm{~m}^{-2}\right)$ appear on the sunward directed side. The electron content enhancement corresponds in time and location with the mid-latitude TEC observations above North America provided in Chi et al. (2005) and Foster and Rideout (2005). (The electron content in their publications is $\sim 15$ TECU higher than those given at 19:40 UT in Fig. 3. The authors map the electron content up to GPS satellite heights, hence, also including the plasmasphere, and naturally resulting in higher TEC.)

Subsequently, the plasma is imaged further toward the nightside, forming a TOI across the dusk side polar cap. 

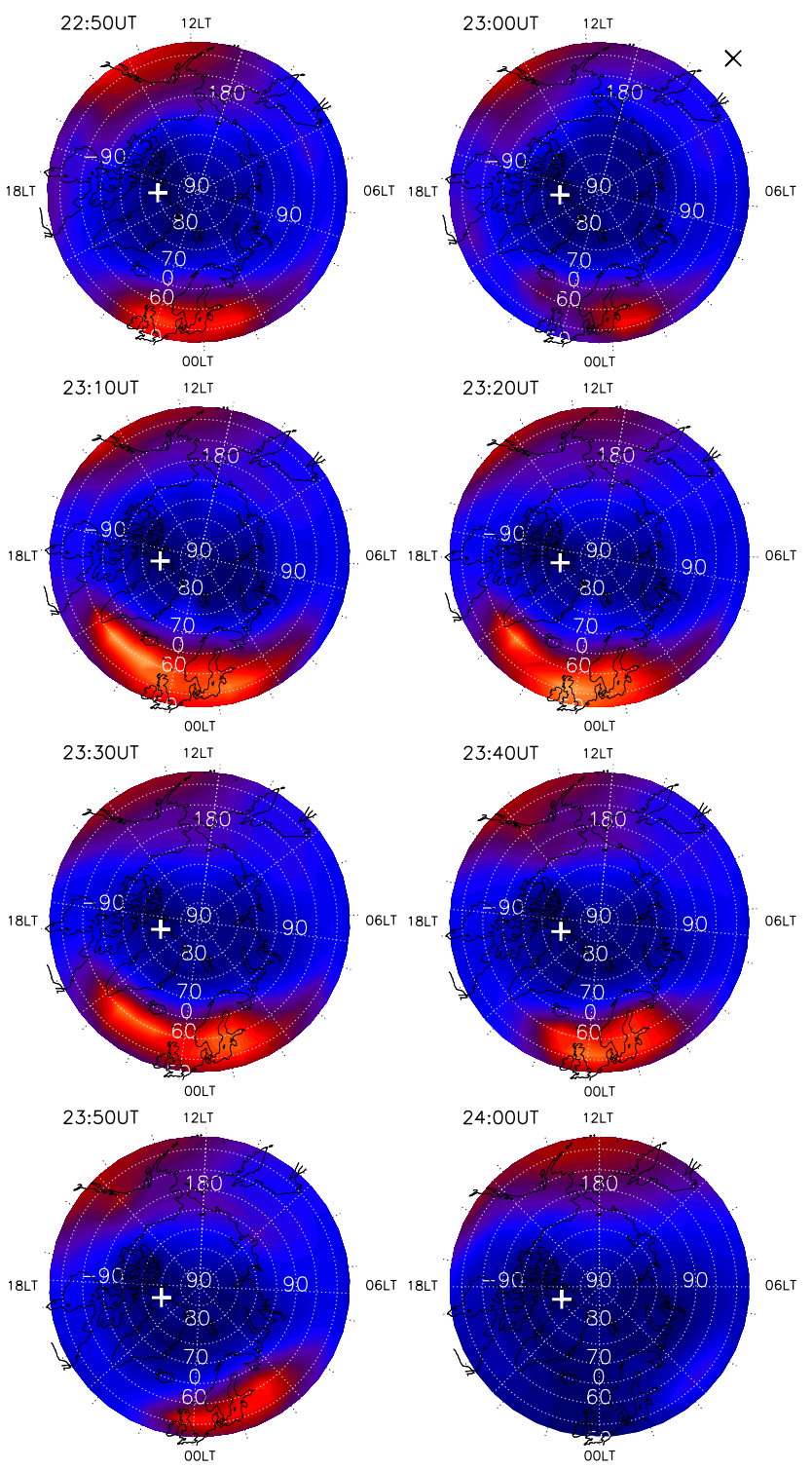

Fig. 4. As for Fig. 3.

The plasma density appears to be patchy. In particular, a region of enhanced TEC values of 40 TECU or higher is imaged at successive times to displace toward night. The high plasma density reaches Northern Europe at $\sim 21: 00$ UT, and the GPS TEC maps shows its weakening after 21:20 UT. This sequence of cross polar plasma images is located during a phase of pronounced southward IMF (c.f. Fig. 2). As introduced above, such patterns are characteristic for large storm events. Our observations agree well with the polar TEC observations for this evening presented in Mitchell et al. (2005), who reported an anti-sunward stream of high plasma density between 21:00 and 21:30 UT similar in location. They also proposed a patch above Northern Canada at 20:00 UT from CHAMP zenith GPS observations.

As discussed above, GPS receivers are located in Northern America, Europe and in the southern and northern regions of Greenland. A gap is present over a wide area in Central

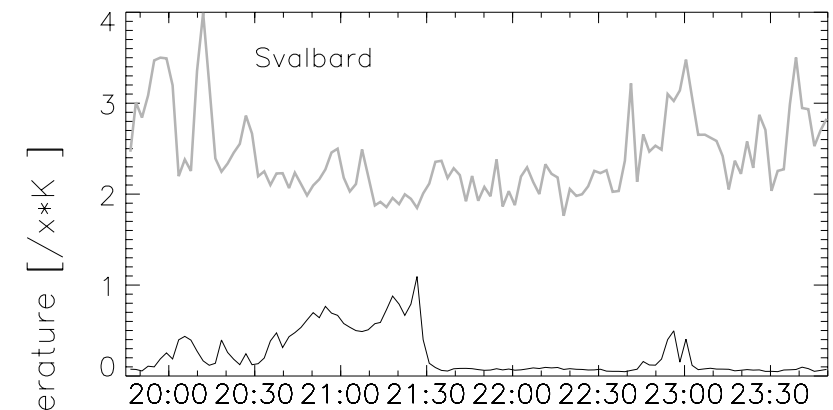

20:00 20:30 21:00 21:30 22:00 22:30 23:00 23:30
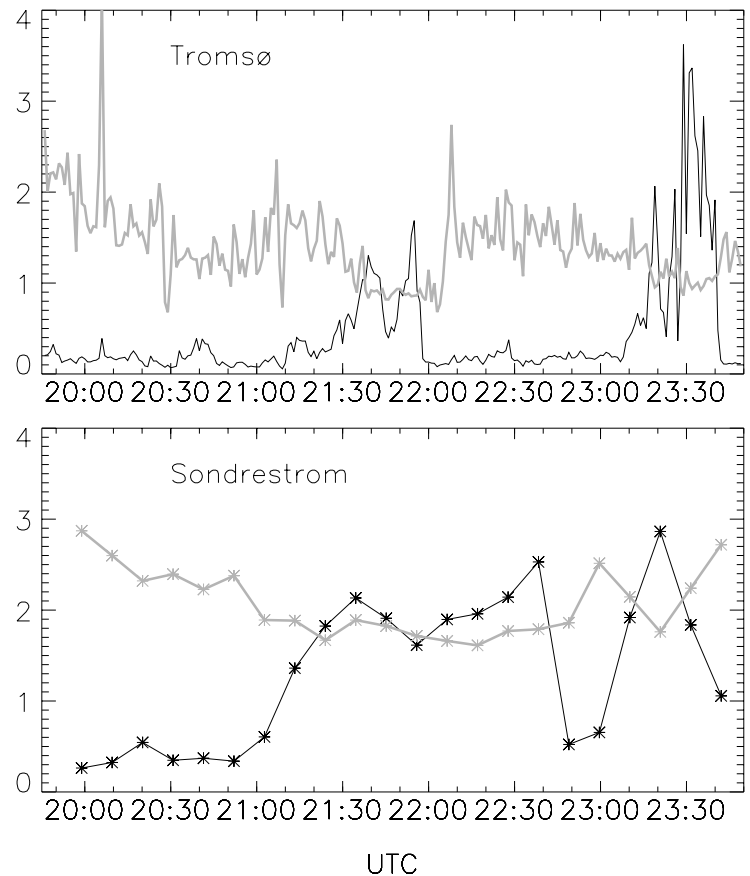

Fig. 5. EISCAT time series of the ESR42 Svalbard and the UHF Mainland radar at Troms $\varnothing$ at $410 \mathrm{~km}$ altitude, as well as of the Sondrestrom radar at $428 \mathrm{~km}$ for 30 October 2003: electron density (black line) and temperature (grey line) scaled by $x=1000$ for Svalbard and Sondrestrom, and by $x=2000$ for Troms $\varnothing$. Asterisks on the lowest panel give the sampling time of data.

Greenland, which makes the intensity and location of the TOI uncertain there. In particular, the western side of the imaged patch above Northern Europe cannot clearly be determined from the GPS data. The observations of the TOI evolution will be completed later using IS radar observations.

Figure 4 shows assimilation maps of vertical TEC for a later time between 22:50 UT and 24:00 UT. The maps are provided here with a resolution of $10 \mathrm{~min}$. The distribution of ionospheric TEC from 22:10 to 22:40 UT (not shown here) did not significantly change on the maps. They are similar to those at 22:00 and 22:50 UT: regions of enhanced TEC of $\sim 20$ TECU at the night- and dayside and low TEC values below 10 TECU inside the polar cap. At 23:10 UT, however, a sudden longitudinal expansion of the nightside plasma is visible in Fig. 4. The plasma band remains intense and large until 23:30 UT, and its size reduces at 23:40 UT. The following extremely fast depletion of the nightside plasma to well below 10 TECU at 24:00 UT is remarkable. 
Again, the GPS TEC maps allow only a restricted interpretation of the plasma density expansion. In addition to the data gap over Central Greenland, the receiver at southern Greenland was not available from 21:50-22:50 UT. Therefore, we have no information about the dusk side during that time. We can tell, however, that the second phase of enhanced nightside TEC was not accompanied nor directly preceded by similarly high values at the dayside. GPS receivers available above Northern America (c.f. Fig. 1) did monitor low electron content.

Figure 5 shows a time series of electron density and electron temperature from the ESR42 at Svalbard and the EISCAT Mainland radar at Troms $\varnothing$ at about $410 \mathrm{~km}$ altitude, as well as from the Sondrestrom radar at $428 \mathrm{~km}$. These altitudes were chosen as being representative for the upper $\mathrm{F}$ region, which is best comparable with TEC maps, since GPS TEC is dominated by the contribution of the $\mathrm{F}$ region plasma. The radar locations are given in Fig. 1. The Svalbard radar monitors increased electron density between 20:50 UT and 21:30 UT, with an electron temperature of $\sim 2000 \mathrm{~K}$ after 21:10 UT. The Troms $\varnothing$ radar measured increased electron density several minutes later from 21:35-22:00 UT accompanied by an electron temperature decrease to $2000 \mathrm{~K}$ from ambient values above $3000 \mathrm{~K}$. The Sondrestrom radar shows an enhancement of the electron density after 21:00 UT, also coinciding with electron temperature values of $2000 \mathrm{~K}$. The coincidence of high electron density and low temperature indicate that the plasma was transported rather than created locally, for example, by soft particle precipitation (Blelly et al., 2005). In particular, an F region electron temperature of $\sim 2000 \mathrm{~K}$ is typical for transported dayside mid-latitude plasma (Foster et al., 2005). Accounting for very similar electron temperatures of $\sim 2000 \mathrm{~K}$ at all radar sites, we probably observe transported plasma with the same origin. The time of first observation above Svalbard coincides fairly well with the time when the region of high plasma content on the assimilation maps reached the nightside polar cap. Therefore, we believe that the IS radar observations reflect the arrival of the TOI on the nightside. The structured series and the sharp rise and fall of electron density at the radar sites support the existence of a patchy structure inside the TOI which is also seen on the GPS TEC maps in Fig. 3.

The uneven distribution of GPS receivers, and especially the data gap over Central Greenland was mentioned earlier (Figs. 3 and 4). The Sondrestrom radar observations may replace our lack of information about this region. One feature of the Sondrestrom time series is the rather late rise of electron density after 21:00 UT although the observation area is located westward, for example, toward day, from the two EISCAT radars. We may speculate that the location of the TOI moved lower in latitude around 21:00 UT and appeared then also at Sondrestrom. In Fig. 3, however, we observe high TEC in Northern Greenland at 20:40 UT, while the centre of the remaining plasma stream is over southern Greenland at 21:00 UT. Probably the most striking feature is the much longer duration of that first sequence of elevated plasma above Sondrestrom than above Northern Eu- rope. This tells us that the westward edge of the plasma patch observed above Europe at that time is probably not as sharp as imaged on the maps, but it is still connected with the dayside by a continuous plasma stream. It further indicates that the TOI may have persisted during the entire period of southward IMF, but with the lower extent toward the nightside. However, half an hour after the change to positive values of the IMF $B_{z}$ at the ACE satellite, the Sondrestrom electron content decreases sharply and the electron temperature rises, as was observed earlier at the EISCAT radars.

Despite the regional lack of GPS data above Sondrestrom, the TEC maps might be used to estimate the drift of the plasma structures inside the TOI. By following the centre of the large patch displayed from Northern Canada toward Svalbard, Stolle et al. (2005b) derived a structure velocity of $\sim 1600 \mathrm{~ms}^{-1}$ between 20:30 UT and 20:50 UT, and of $\sim 800 \mathrm{~ms}^{-1}$ until 21:20 UT from successive images. These values were found to be in agreement with former patch observations or modelling results. We infer a velocity of $844 \mathrm{~ms}^{-1}$ from the arrival times of the plasma enhancement at the EISCAT radars (at 21:10 UT in Svalbard, at 21:30 UT in Troms $\varnothing$ ), which corresponds well with simultaneous estimations in Stolle et al. (2005b). An uncertainty of their high velocity estimate above Northern Greenland cannot be excluded since important information southward of the structure were missing. The patch centre was probably poorly determined by using only the maps.

After a period of very low electron density of $\sim 0.110^{12} \mathrm{~m}^{-3}$ above Svalbard, the high latitude radar gives briefly increased values up to $\sim 0.510^{12} \mathrm{~m}^{-3}$ at $22: 58 \mathrm{UT}$, which are accompanied by a high electron temperature of almost $3500 \mathrm{~K}$. These observations indicate local plasma production, for example, by soft particle precipitation. The GPS TEC maps in Fig. 4 do not show similar plasma content enhancements, although Svalbard GPS data are available for 23:00 UT. The plasma event was too restricted in location and short in time to be actually resolvable by the TEC mapping technique.

Increased electron density was observed at the Sondrestrom radar at 23:10 UT and, just few minutes later, at 23:15 UT, a sequence of elevated electron content also started above Troms $\varnothing$. At both sites, very high electron density values of $310^{12} \mathrm{~m}^{-3}$ occurred, together with a decrease in electron temperature to about $2000 \mathrm{~K}$. Therefore, the convective origin of the plasma is again suggested here. At the same time, Fig. 4 shows the increase in the nighttime plasma content. A fairly good local coincidence with the radar observations is found. This late evening sequence of observations was made during a time of large oscillations of the IMF $B_{z}$ (c.f. Fig. 2).

\section{Discussion and summary}

We present ionospheric data obtained from GPS assimilation electron content maps and three north polar IS radars during a major storm event on 30 October 2003. The different 
observational methods, especially in scale, availability, and temporal resolution complement one another, to construct a more comprehensive picture of the north polar ionosphere.

With these instruments we are able to monitor the electron content trace of a continuous TOI, starting at 19:40 UT. The TOI persisted during the whole period of southward IMF $B_{z}$ until about 22:40 UT while its largest extension toward the nightside is found between 21:00-22:00 UT. The structured appearance of the electron content distribution on the TEC maps and in the IS radar electron density time series indicate the formation of plasma patches. We found an $\mathrm{F}$ region temperature of $\sim 2000 \mathrm{~K}$ and a velocity of the plasma structures of $\sim 800 \mathrm{~ms}^{-1}$. Both are typical values for transported dayside mid-latitude plasma (Foster et al., 2005).

After a short period of low values above the polar cap GPS and radar sites the $\mathrm{F}$ region plasma density re-enhanced at 23:10 UT. This nightside plasma observation is restricted to below $70^{\circ}$ geographic north from the GPS and was monitored at the Sondrestrom and Troms $\varnothing$ radar sites. Simultaneous low electron temperatures support the convective origin of the plasma. At this stage, it is difficult to tell if these observations are a continuity of the TOI, for example, with southern stream location, or if other processes are responsible for it, since we have no preceding information about the dusk side. We may, however, summarise possibly relevant observations: (1) the plasma band was located at the southern edge of the auroral region. The Scandinavian IMAGE magnetometer array (http://www.ava.fmi.fi/image/) gives the location of the electrojet between $65^{\circ}$ and $67^{\circ}$ geographic north; (2) just a few minutes before, at 22:58 UT, a short-lived plasma production event was observed at Svalbard. Although we cannot tell its dimension, we know that plasma production must have occurred in the polar cap; (3) the nightside plasma increase was not accompanied nor preceded by similar TEC values on the dayside polar region. A strong plasma stream across the central polar cap can be excluded; (4) the plasma enhancement shows a decreased electron temperature of $2000 \mathrm{~K}$ which indicates its convective origin; (5) the expansion occurred right after 23:10 UT, during a time when the IMF $B_{z}$ suffered from two rapid oscillations with large amplitudes. These can be related to the behaviour of the night side ionosphere, at least in timely connection, for example, causing a changing convection pattern. The last two points could support the continuity of the TOI.

The multi-instrumental use for ionospheric specification provides observational evidence of anti-sunward cross polar plasma tongues simultaneously over large areas, for example, over the polar cap. Both the TOI and discrete polar patches form steep electron density gradients along their edges. These are of particular interest for navigation and communication system applications, since radio wave scintillation have been frequently related to such structures (Basu et al., 1995, and references therein). Coincidently with imaged plasma density enhancements near Svalbard at $\sim 21: 00$ UT shown above, Mitchell et al. (2005) also observed enhanced scintillation activity.

The experimental approach to obtain the electron density distribution is useful, for example, it completes plasma patch predictions of numerical models (e.g., Sojka et al., 1994). The availability, in principle, of the 3-D electron density maps of data assimilation allows in addition to the specification of the electron content, the estimate of the velocity and the path of the plasma. Hereby, the growing number of navigational receivers, on the ground as well as on board future scientific polar orbiting satellites (e.g. FORMOSAT3/COSMIC, Cyranoski, 2001), is a promising issue for its further improvement. This paper shows the successful use of an ensemble of electron content and temperature observations, to provide snapshots during polar convection processes. The combination of these with drift measurements and precipitation data can support and advance the specification of the convection pattern and may further distinguish between plasma transport or production.

Acknowledgements. We acknowledge the use of the ground-based GPS data supplied by IGS and SOPAC. Many thanks to V. Wilken for preprocessing the SOPAC data. The operational support of the CHAMP mission by the German Aerospace Center (DLR) and the financial support for the data processing by the Federal Ministry of Education (BMBF), as part of the Geotechnology Programme, are gratefully acknowledged. EISCAT is a scientific association of national funding agencies of France, Finland, Germany, Japan, Norway, Sweden and the United Kingdom. The authors thank C. Lathuillere for her helpful support in EISCAT data processing. The Sondrestrom radar program receives support from the U.S. National Science Foundation (NSF) under the cooperative agreement ATM-0334122 with SRI International. We acknowledge the use of the ACE data supplied from the ACE Science Center at Caltech.

Topical Editor M. Pinnock thanks J. Foster and another referee for their help in evaluating this paper.

\section{References}

Barthélemy, M., Culot, F., Kofman, W., Lathuillere, C., Lilensten, J., Perrin, J.-M., Simon, C., and Thuillier, G.: Response of the polar ionosphere to interplanetary coronal mass ejections observed on 29th and 30th of October 2003, presented at 35th COSPAR Scientific Assembly, Paris, France, 2004.

Basu, S., Basu, Su., Sojka, J. J., Schunk, R. W., and MacKenizie, E.: Macroscale modeling and mesoscale observations of plasma density structures in the polar cap, Geophys. Res. Lett. 22(8), 881-884, 1995.

Bilitza, D.: International Reference Ionosphere: IRI-90, Nat. Space Sci. Data Cent., Greenbelt, Md., 90-22, 1990.

Bilitza, D.: International Reference Ionosphere 2000, Radio Sci., 36(2), 261-275, 2001.

Blelly, P.-L., Lathuillere, C., Emery, B., Lilensten, J., Fontanari, J., and Alcaydé, D.: An extended TRANSCAR model including ionospheric convection: simulation of EISCAT observations using inputs from AMIE, Ann. Geophys., 23, 419-431, 2005,

SRef-ID: 1432-0576/ag/2005-23-419.

Chi, P. J., Russel, C. T., Foster, J. C., Mildwin, M. B., Engebretson, M. J., and Mann, I. G.: Density enhancement in plasmasphereionosphere plasma during the 2003 Halloween Superstorm: Observations along the 330th meridian in North America, Geophys. Res. Lett. 32, L03S05, doi:10.1029/2004GL021480, 2005. 
Cyranoski, D.: Array system promises global atmospheric monitoring, Nature, 144, 228, doi: 10.1038/35077281, 2001.

Dungey, J. W.: Interplanetary magnetic field and the auroral zones, Phys. Rev. Lett., 6(2), 47-48, 1961.

Foster, J. C., Coster, A. J., Erickson, P. J., Holt, J. M., Lind, F. D., Rideout, W., McCready, M., van Eyken A., Barnes, R. J., Greenwald, R. A., and Rich, F. J.: Multiradar observations of the polar tongue of ionisation, J. Geophys. Res., 110, A09S31, doi:10.1029/2004JA010928, 2005.

Foster, J. C. and Ridout, W.: Midlatitude TEC enhancement during October 2003., Geophys. Res. Lett., 32, L12S04, doi:10.1029/2004GL021719, 2005.

Foster, J. C.: Storm-time plasma transport at middle and high latitudes, J. Geophys. Res., 98, 1675-1689, 1993.

Gallagher, D. L., Craven, P. D., and Comfort, R. H.: Global core plasma model, J. Geophys. Res., 105(A8), 18 819-18 833, 2000.

Gopalswamy, N., Barbieri, L., Lu, G., Plunkett, S. P., and Skoug, R. M.: Introduction to the special section: Violent Sun-Earth connection events of October-November 2003, Geophys. Res. Lett. 32, L03S01, doi:10.1029/2004GL022348, 2005.

Heise, S., Stolle, C., Schlüter, S., and Jakowski, N.: Differential Code Bias of GPS receivers in Low Earth Orbit: An Assessment for CHAMP and SAC-C, In: Earth Observation with CHAMP: Results from Three Years in Orbit, edited by: Reigber, Ch., Lühr, H., Schwintzer, P., and Wickert, J., Springer-Verlag BerlinHeidelberg, p. 465-470, 2005.

Kelly, J. D., Heinselman, C. J., Vickrey J. F., and Vondrak, R. R.: The Sondrestrom radar and accompanying ground-based instrumentation, Space Sci. Rev., 71, 1-4, 797-813, 1995.

Kersley, L., Pryse, S. E. , Denton, M. H., Bust, G., Fremouw, E., Secan, J., Jakowski, N., and Bailey, G. J.: Radio tomographic imaging of the northern high-latitude ionosphere on a wide geographic scale, Radio Sci., 40, RS5003, doi:10.1029/2004RS003103, 2005.

Mitchell, C. N., Alfonsi, L., De Franceschi, G., Lester, M., Romano, V., and Wernik, A. W.: GPS TEC and scintillation measurements from the polar ionosphere during the October 2003 storm, Geophys. Res. Lett., 32, L12S03, doi:10.1029/2004GL21644, 2005.

Reigber, Ch., Lühr, H., and Schwinter, P.: CHAMP mission status, Adv. Space Res., 30, 129-134, 2002.

Rishbeth, H. and van Eyken, A. P.: EISCAT: early history and the first ten years of operation, J. Atmos. Terr. Phys., 55. 525-542, 1993.

Sojka, J. J., Bowline, M. D., and Schunk, R. W.: Patches in the polar ionosphere: UT and seasonal dependence, J. Geophys. Res., 99(A8), 14 959-14 970, 1994.
Sojka, J. J., Bowline, M. D., and Schunk, R. W., Decker, D. T., Valladares, C. E., Shehan, R., Anderson, D. N., and Heelis, R. A.: Modeling polar cap F-region patches using time varying convection, Geophys. Res. Let., 20(17), 1783-1786, 1993.

Skoug, R. M., Gosling, J. T., Steinberg, J. T., McComas, D. J., Smith, C. W., Ness, N. F., Hu, Q., and Burlaga, L. F.: Extremely high speed solar wind: 29-30 October 2003, J. Geophys. Res., 109, A09102, doi:10.1029/2004JA010494, 2004.

Stolle, C.: Three-dimensional imaging of ionospheric electron density fields using GPS observations at the ground and onboard the CHAMP satellite, Rep. Inst. Meteorol. Univ. Leipzig, 35, PhD Thesis, 2004.

Stolle, C., Jakowski, N., Schlegel, K., and Rietveld, M.: Comparison of high latitude electron density profiles obtained with the GPS radio occultation technique and EISCAT measurements, Ann. Geophys., 22, 2015-2022, 2004,

\section{SRef-ID: 1432-0576/ag/2004-22-2015.}

Stolle, C., Schlüter, S., Jacobi, Ch., Jakowski, N., Heise, S., and Raabe, A.: Three-dimensional monitoring of the polar ionosphere with ground- and space-based GPS, in: Earth Observation with CHAMP: Results from Three Years in Orbit, edited by: Reigber, Ch., Lühr H., Schwintzer, P., and Wickert, J. SpringerVerlag Berlin-Heidelberg, p. 477-482, 2005a.

Stolle, C., Schlüter, S., Heise, S., Jacobi, Ch., Jakowski, N., Friedel, S., Kürschner, D., and Lühr, H.: GPS ionospheric imaging of the north polar ionosphere on 30 October 2003, Adv. Space Res., 36(11), 2201-2206, 2005b.

Valladares, C. E., Basu, S., Buchau, J., and Friis-Christensen, E.: Experimental evidence for the formation and entry of patches into the polar cap, Radio Sci., 29(1), 167-194, 1994.

Weber, E. J., Tsunoda, R. T., Buchau, J., Sheehan, R. E., Strickland, D. J., Whiting, W., and Moore, J. G.: Coordinated measurements of auroral zone plasma enhancements, J. Geophys. Res., 90, 6497-6513, 1985.

Weimer, D. R.: An improved model of ionospheric electric potential including substorm perturbations and application to the Geospace Environment Modeling November 24, 1996 event, J. Geophys. Res., 106(A1), 407-416, 2001.

Zhao, B., Wan, W., and Liu, L.: Response of equatorial anomaly to the October-November 2003 superstorm, Ann. Geophys., 23, 693-706, 2005,

SRef-ID: 1432-0576/ag/2005-23-693. 